\title{
ICT, activity space-time and mobility: new insights, new models, new methodologies
}

\author{
Eran Ben-Elia ${ }^{1} \mathbb{D} \cdot$ Feng Zhen $^{2}$
}

Published online: 27 March 2018

(C) Springer Science+Business Media, LLC, part of Springer Nature 2018

Over three decades have passed since research on the complex interrelationships between Information and Communication Technologies (ICT) and travel behaviour began. Since then much has changed. Broadly speaking researchers have been chasing a complex and bi-directional moving target with both the development of digital technologies (what we refer to as three Internet generations) and changes to human behaviours coinciding side by side. As both transportation technologies and ICT contribute to remote activities, the impact of ICT on individuals' activities and related travel behaviour have been discussed. It is not surprising because untangling this issue is the basis of understanding travel behaviour in information age. In the mid $80 \mathrm{~s}$ and early $90 \mathrm{~s}$ scholars were trying to disentangle how telecommunications (as they were then called) would likely influence activity and travel patterns and an initial set of hypotheses were established by Salomon and Mokhtarian (Mokhtarian 1990; Salomon 1986). According to their framework telecommunications could substitute, complement, modify travel (route, mode, timing or destination) or have no effect at all. This simple and direct framework fitted well to the rather simple information technology of the time. The 1st Internet generation can traced to the opening of the World Wide Web (www) initially as a unidirectional protocol for passing on information content from producers to the users on sedentary end devices (desktops). Research focused mainly on the substitution/complementary relationships between virtual and physical activities especially e-working (teleworking/telecommuting-Mokhtarian and Salomon 1994) and e-shopping and how they affect the demand for travel (Cao 2012; Zhai et al. 2017). Another strand of research involved the influence of information on modification of travel choices based on the abundance of travel planners available on the web (Ben-Elia

Eran Ben-Elia

benelia@bgu.ac.il

Feng Zhen

zhenfeng@nju.edu.cn

1 Department of Geography and Environmental Development, Ben-Gurion University of the Negev, Beersheba, Israel

2 Department of Urban Planning and Design, Nanjing University, Nanjing, China 
and Avineri 2015; Chorus et al. 2006). A main conclusion resulting from this literature is that no simple unified theory can fit these complex phenomena.

Technology continued to evolve with the 2 nd generation of the Internet introducing two way communication and sharing and exchange of information between users and suppliers. The older form of IT was transformed to ICT. This led to the establishment of digital social networks and the widespread ability to maintain extensive social ties without geographic proximity (Tillema et al. 2010). Second and more importantly was the transition from stationary devices to mobile devices and the move from place-based to person based telecommunications (Sharmeen et al. 2014). Mobile telephony and broadband were major game changers allowing people to renegotiate their mandatory and non-mandatory activities more effectively through various channels including voice, text, email and instant messaging (van den Berg et al. 2012). For example, mobile e-devices enable individuals to engage in activities remotely reducing the need of physical co-presence. With this evolution, new thoughts started appearing how ICT and mobility possibly interact. ICT is loosening the bond between activities and fixed locations and times, which has expanded the ways of engaging in activities including simultaneous time use, multitasking, etc. (Mokhtarian et al. 2006). As a result, the notion of temporal and spatial fragmentation of activities has been proposed (Lenz and Nobis 2007). The activity fragmentation theory suggested ICT is associated with the breakup of activities into smaller temporal chunks that can take place in different places and times (Ben-Elia et al. 2014). This idea explained the infringement of home activities on workplaces during the day and work activities at the home during the evening (Alexander et al. 2010). However the theory of fragmentation was not able to explain how this comes about. In addition the notion of travel time as dead time was being assertively challenged especially on public transport both for work related and leisure related activities (Jain and Lyons 2008; Line et al. 2011; and see the discussion in the 1st round table in the Epilogue), especially when ICTs deeply permeate into individuals' daily life which results in the facts that a lot of tele-activities can be conducted during the travel, which enables the trains, buses, and cars to become a moving space for conducting other activities (Wang et al. 2015). In recent years, research on travel time use in the context of different national cultures and with different transportation modes are expanded greatly, especially research on developing countries.

Despite the mounting evidence of more mobile and complex interrelationships between ICT and human behaviours the lack of an adequate theory remains a persistent problem. A more elaborate framework involving the notion of a fluid tapestry of relationships between physical and virtual activity participation was suggested by Mokhtarian and Tal (2013). While some activities can never be replaced by virtual means, others remain purely virtual and many mixtures can exist in between, including 'reallocation' of money or time resources through ICT. This framework has not been properly studied and thus has not yet materialized into a full blown theory whilst the simplicity of the substitution-complementarity description still maintains its appeal (see 2nd roundtable discussion in the Epilogue), despite the fact that most researchers agree it is obsolete.

Not only is there a lack of sound theory to date but it seems that with the emergence of the 3rd Internet generation - the Internet of Things (IoT) - we are on the verge of a new era of transportation and ICT fusion into an intricate personal mobility tool kit (Grieco and Urry 2011). IoT will connect a multitude of objects and appliances online with tremendous implications for everyday life. People might not need to deal with everyday maintenance tasks like grocery shopping if their refrigerator or pantry will be able to recognize what they need and order supplements online (Hubers et al. 2011; Lyons 2015). IoT will also manifest in connected mobility with cars and other vehicles communicating between each 
other in real time and with road/rail infrastructures and traffic management centres. Naturally contemplating about the future of autonomous mobility is beyond this editorial but it should also be noted as a potential source for large scale changes in lifestyles, time use, activity participation and possibly even urban form (Fagnant and Kockelman 2014; Krueger et al. 2016; Shladover 2017; Thomopoulos and Givoni 2015).

As the degree of uncertainty and innovation grows so does the need for novel methodologies to tackle the inherent behavioural complexity. Luckily, the increasing use of ICT themselves-via mobile phones and apps, smartcards, credit-cards etc., is passively generating large amounts of data-big data - that researchers can mine to capture the rhythms of everyday life in space and time. It has been recently shown that travel demand, transportation management and urban planning have paid increasing attention to big data. Originally, most studies have explored characteristic of individuals' spatial-temporal travel behaviour and its interaction with urban space (Ahas et al. 2010; Licoppe et al. 2008). In recent years, big data and social media data are employed by transport modellers for modelling transport related issues (Hasan and Ukkusuri 2015; Hasan et al. 2016; Rashidi et al. 2017). At the same time researchers are actively using dedicated apps to monitor and learn about dynamic spatiotemporal behaviours. Nevertheless neither passive big data nor apps are a panacea and many obstacles remain in their application (Chen et al. 2016). In this regard, with the rise of the Internet City and the implementation of smart city strategy (Zhen et al. 2015), China has shown promise for providing wide access to many Big Data sources including mobile phone records, smartcard and local social networks some of which is demonstrated in our special issue. We should not forget to mention the exciting applications of experience-based panels, serious games and virtual reality as non-traditional approaches for studying adoption of innovation (Stathopoulos et al. 2017).

Thus this special issue aims to provide a platform for scholars to share their new research and findings contributing to new conceptual, methodological, and/or empirical advances on the relationships between travel behaviour, activity, time use and ICT, new insights and models on ICT induced trade-offs between mobility, activities and time, spent in between physical and virtual spaces, and new methodologies to collect and analyse data from active and passive big data sources including social media and specifically tailored APPs on travel, time use and activities. Moreover, these topics in the context of China need to be paid urgent attention as deep ICT permeation in Chinese residents' daily activities and travel behaviour, and the construction of smart city in China is in fully swing which creates new prospect for the transformation of residents' activities. Of course, not all of these topics have been covered in the special issue.

Ettema proposes activity theory as a framework to analyse the impact of smartphone apps on travel and activities. Based on an explorative analysis on Whatsapp and travel feedback apps, his study suggests that the activity systems of each app differ largely in terms of object, motive, outcomes, community and rules.

Mulley and Ma use 3-year panel data collected by GPS tracking and a conventional survey methodology in northern Adelaide, South Australia, to examine whether the social marketing program which targeted reducing vehicle kilometres travelled, TravelSmart, had a sustained impact. Their results indicate that both driving time the driving distances of TravelSmart participants have a declining trend over the 3 tears, albeit with variations among participants with different socio-demographic and built environment characteristics.

Song, Fan, Li and Ji develop Python scripts to modify and extend visualization techniques based on a data cube of four dimensions-space, date, time, and user. Based on 1 month of smartcard data with boarding and/or alighting information during October, 2013, the data cube technique is adopted to understand space-time travel patterns of 
Nanjing rail transit users. The visualizations of two-dimensional slices of the data cube provide novel insights to the impacts of National Holiday on smartcard usage and disparities among various user groups.

Zegras, Li, Kilic et al. assesses the use of a smartphone-based promoted-recall household travel survey, Future Mobility Sensing (FMS), in Dar-es-Salaam. Their experiment reveals various potential social and technical challenges. Non-random, non-participation and non-response seems to exist. Therefore, it is important to include enhanced mobile phone training of participants and/or improving the interviewers' verification procedure.

Loo and Wang explore the multifunctional role of home from the perspective of individual's time use on e-working and e-shopping at home. Using a household survey of 608 full-time paid employees who conducted e-activities at home in Nanjing, they analyse the characteristics and patterns of home-based e-working and e-shopping. Their results indicate that the rich e-activities taking place at home has gradually enriched the function of home in people's daily life.

Zhu, Wang, Jiang and Zhou examine whether metropolitan size impacts telecommuting based on data from 2001 and 2009 National Household Travel Surveys in the US. Their findings suggest that the policies that promote telecommuting may increase, rather than decrease as expected, people's travel demand, regardless of the size of the metropolitan size. Besides, the complementary impact of telecommuting on daily travel is lower in larger metropolitan statistical areas.

Suel, Daina and Polak adopt the hazard based duration models to examine the effect of online shopping on the whole shopping activity patterns and personal trips, using 1 year long longitudinal grocery shopping purchase data from London shoppers. Their results demonstrate that shopping online does not have a significant effect on overall shopping activity frequency, yet affects shopping trip rates.

Dong, Cirillo and Diana extend the traditional analysis of leisure activity participation by including leisure activities that require the use of a personal computer. Specifically, they examine the substitution effects with both in-home and out-of-home leisure activities and the time budget allocated to each of them, based on data extracted from the American Time Use Survey. Their findings indicate that there is little substitution effects between leisure with personal computer and the relative time spent on it, with inhome and out-of-home leisure episodes.

Tang, Zhen, Cao and Mokhtarian present the first analysis of high-speed-rail (HSR) passengers' travel time use in China. Using a survey conducted on the Shanghai-Nanjing corridor, they find that $96 \%$ of the respondents use ICT during their HSR journey and more interestingly, that most passengers spend some of their travel time on work-related activities. Their results also indicate that the items carried, advance planning, and work-related travel attributes heavily influence activity participation while travelling.

At the end of this issue we have provided the reader with an Epilogue that collates the research notes of three cross-cutting research themes discussed during the international symposium on "ICT, Activity, Time Use and Travel" organized by Nanjing University and International Association for China Planning (IACP) in July 2016 in Nanjing, China, that inspired this special issue.

This is only the starting point in ICT and travel research. Technological developments have had, and still have, a major impact on our society and daily life and they are likely to continue playing significant role in the future. Therefore, there are still many unanswered questions which need to be addressed and investigated in-depth. Certainly, this requires concerted efforts and contributions of scholars from worldwide. 
Special thanks to Prof. Kay Axhausen, Editor in Chief, Ms. Suganya Manikandan and Mr. Gopi Mohan Journal publishing office, Prof. Jason Cao, University of Minnesota, for motivating the special issue proposal and all the dedicated reviewers that supported the peer-review of this special issue.

\section{References}

Ahas, R., Aasa, A., Silm, S.: Daily rhythms of suburban commuters' movements in the Tallinn Metropolitan Area: case study with mobile positioning data. Transp. Res. Part C 18(1), 45-54 (2010)

Alexander, B., Ettema, D., Dijst, M.: Fragmentation of work activity as a multi-dimensional construct and its association with ICT, employment and sociodemographic characteristics. J. Transp. Geogr. 18(1), 55-64 (2010)

Ben-Elia, E., Avineri, E.: Response to travel information: a behavioural review. Transp. Rev. 35(3), 352-377 (2015)

Ben-Elia, E., Alexander, B., Hubers, C., Ettema, D.: Activity fragmentation, ICT and travel: an exploratory path analysis of spatiotemporal interrelationships. Transp. Res. Part A Policy Pract. 68, 56-74 (2014)

Cao, X.J.: The relationships between e-shopping and store shopping in the shopping process of search goods. Transp. Res. Part A Policy Pract. 46(7), 993-1002 (2012)

Chen, C., Ma, J., Susilo, Y., Liu, Y., Wang, M.: The promises of big data and small data for travel behavior (aka human mobility) analysis. Transp. Res. Part C Emerg. Technol. 68, 285-299 (2016)

Chorus, C.G.C., Molin, E.J.E., van Wee, B., Van Wee, B: Travel information as an instrument to change car-drivers' travel choices: a literature review. Eur. J. Transp. Infrastruct. Res. 6(4), 335-364 (2006). Retrieved from http://repository.tudelft.nl/assets/uuid:098105c4-612e-4814-93b9-bcd34aa71d 24/2006_04_03.pdf

Fagnant, D.J., Kockelman, K.: Preparing a nation for autonomous vehicles: opportunities, barriers and policy recommendations. In: Transportation Research Board 93rd Annual Meeting (2014)

Grieco, M., Urry, J.: Mobilities: New Perspectives on Transport and Society. Ashgate Publishing Ltd, Farnham (2011)

Hasan, S., Ukkusuri, S.V.: Location contexts of user check-ins to model urban geo life-style patterns. PLoS ONE 10(5), e0124819 (2015)

Hasan, S., Ukkusuri, S.V., Zhan, X.: Understanding social influence in activity-location choice and life-style patterns using geo-location data from social media. Front. ICT 3, 10 (2016)

Hubers, C., Lyons, G., Birtchnell, T.: The unusual suspects: the impact of non-transport technologies on social practices and travel demand. In: Proceedings of the 43rd universities transport study group conference, Milton Keynes, UK, 5th-7th January 2011. http://eprints.uwe.ac.uk/14151

Jain, J., Lyons, G.: The gift of travel time. J. Transp. Geogr. 16(2), 81-89 (2008)

Krueger, R., Rashidi, T.H., Rose, J.M.: Preferences for shared autonomous vehicles. Transp. Res. Part C 69, 343-355 (2016). https://doi.org/10.1016/j.trc.2016.06.015

Lenz, B., Nobis, C.: The changing allocation of time activities in space and time by the use of ICT-fragmentation as a new concept and empirical results. Transp. Res. Part A 41(2), 190-204 (2007)

Licoppe, C., Diminescu, D., Smoreda, Z., Ziemlicki, C.: Using mobile phone geolocalisation for 'sociogeographical' analysis of co-ordination, urban mobilities, and social integration patterns. Tijdschrift voor Economische en Sociale Geografie 99(5), 584-601 (2008)

Line, T., Jain, J., Lyons, G.: The role of ICTs in everyday mobile lives. J. Transp. Geogr. 19(6), 1490-1499 (2011)

Lyons, G.: Transport's digital age transition. J. Transp. Land Use 8(2), 1-19 (2015)

Mokhtarian, P.L.: A typology of relationships between telecommunications and transportation. Transp. Res. Part A Gen. 24(3), 231-242 (1990)

Mokhtarian, P.L., Tal, G.: Impacts of ICT on travel behavior: a tapestry of relationships. In: The Sage Handbook of Transport Studies, Vol. 14, pp. 241-260 (2013)

Mokhtarian, P.L., Salomon, I.: Modeling the choice of telecommuting: setting the context. Environ. Plan. A 26(5), 749-766 (1994)

Mokhtarian, P.L., Salomon, I., Handy, S.L.: The impacts of ICT on leisure activities and travel: a conceptual exploration. Transportation 33(3), 263-289 (2006)

Rashidi, T.H., Abbasi, A., Maghrebi, M., Hasan, S.: Exploring the capacity of social media data for modelling travel behaviour: opportunities and challenges. Transp. Res. Part C 75, 197-211 (2017) 
Salomon, I.: Telecommunications and travel relationships: a review. Transp. Res. Part A Gen 20(3), 223238 (1986)

Sharmeen, F., Arentze, T., Timmermans, H.: Dynamics of face-to-face social interaction frequency: role of accessibility, urbanization, changes in geographical distance and path dependence. J. Transp. Geogr. 34, 211-220 (2014)

Shladover, S.E. (2017). Connected and automated vehicle systems: introduction and overview. J. Intell. Transp. Syst. (just-accepted), 0

Stathopoulos, A., Cirillo, C., Cherchi, E., Ben-Elia, E., Li, Y.-T., Schmöcker, J.-D.: Innovation adoption modeling in transportation: new models and data. J. Choice Model. 25, 61-68 (2017)

Thomopoulos, N., Givoni, M.: The autonomous car-a blessing or a curse for the future of low carbon mobility? An exploration of likely vs. desirable outcomes. Eur. J. Futures Res. 3(1), 1-14 (2015)

Tillema, T., Dijst, M., Schwanen, T.: Face-to-face and electronic communications in maintaining social networks: the influence of geographical and relational distance and of information content. New Media Soc. 12(6), 965-983 (2010)

van den Berg, P.E.W., Arentze, T.A., Timmermans, H.J.P.: New ICTs and social interaction: modelling communication frequency and communication mode choice. New Media Soc. 14(6), 987-1003 (2012). https://doi.org/10.1177/1461444812437518

Wang, B., Zhen, F., Wei, Z., Guo, S., Chen, T.: A theoretical framework and methodology for urban activity spatial structure in e-society: empirical evidence for Nanjing City, China. Chin. Geogr. Sci. 25(6), 672-683 (2015)

Zhai, Q., Cao, X., Mokhtarian, P.L., Zhen, F.: The interactions between e-shopping and store shopping in the shopping process for search goods and experience goods. Transportation 44(5), 885-904 (2017)

Zhen, F., Wang, B., Wei, Z.: The rise of the internet city in China: production and consumption of internet information. Urban Stud. 52(13), 2313-2329 (2015)

Eran Ben-Elia is a Senior Lecturer at the Department of Geography and Environmental Development at Ben-Gurion University of the Negev, Israel and Head of the GAMES (Game-based models) lab. He received his $\mathrm{PhD}$ in Transportation Science and M.Sc in Urban Planning from the Technion - Israel Institute of Technology. His research focuses on understanding human spatial behaviors using serious games, big data and agent-based simulations, in particular for utilizing ICT and other emerging technologies to promote sustainable travel behaviors and transportation planning.

Feng Zhen is a Professor at the School of Architecture and Urban Planning, Nanjing University, China. He received his Ph.D. degree from Nanjing University, China. His research focuses upon smart city, information geography, big data and urban study, and ICT \& travel behavior. He is the author or co-author of more than 300 scientific publications in both Chinese and English. 